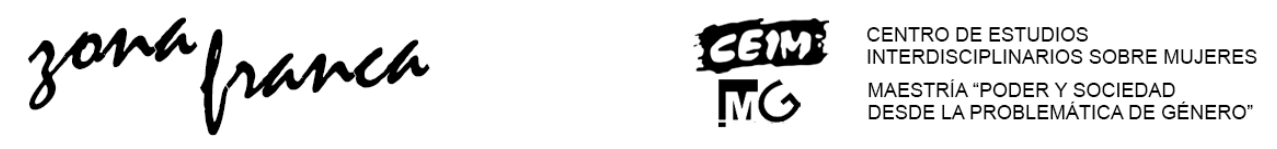

\title{
Yo, cinemática: Cecilia Szperling y sus viñetas de infancia
}

María José Punte*

\section{Resumen}

Echar una mirada feminista sobre la literatura argentina implica desandar un camino construido a partir de una dinámica de lecturas y reapropiaciones, de citas desviadas o interceptadas, así como de silencios y algunos olvidos programáticos. Ya es un hecho que el feminismo ha ocupado una escena protagónica en un presente en donde la literatura y sus creadoras ocupan las calles y los espacios públicos. En ese escenario, asoma un texto que retoma ciertos procedimientos de miniaturización, pero que sirve al objetivo de preguntarse una vez más quién escribe el canon, ese sistema selectivo y productor de jerarquías, y cómo se lo delimita. Se trata de Cecilia Szperling y su "fábula autobiográfica" La máquina de proyectar sueños (2006), un breviario de viñetas de infancia que se entronca en una tradición cultivada, entre otras, por Norah Lange. Este análisis se concentrará en dos elementos: por un lado, la construcción de una biblioteca contra-canónica desde la cual se legitiman otras voces minoritarias (mujeres y sujetos feminizados, infantes); por el otro, el uso de los dispositivos audiovisuales como elemento inseparable para la construcción de una memoria tanto individual como colectiva.

Palabras clave: literatura argentina, infancia, canon, feminismo, Cecilia Szperling.

\section{I, cinematic: Cecilia Szperling and her childhood vignettes}

\section{Abstract}

\footnotetext{
*Profesora titular del Seminario de Análisis del Discurso y profesora adjunta de la materia Literatura y Cine en la Universidad Católica Argentina (Buenos Aires). Realiza investigación en el Instituto de Investigación de Estudios de Género de la Universidad de Buenos Aires, en donde da seminarios en el área de los estudios de género. Contacto: majo.punte@gmail.com
}

Punte, María José. "Yo, cinemática: Cecilia Szperling y sus viñetas de infancia" en Zona Franca. Revista del Centro de estudios Interdisciplinario sobre las Mujeres, y de la Maestría poder y sociedad desde la problemática de Género, №28, 2020 pp. 387-411. ISSN, 2545-6504 Recibido: 16 de junio 2020; Aceptado: 16 de octubre 2020

Revista Zona Franca- Centro de estudios interdisciplinario sobre las mujeres (CEIM)- Maestría poder y sociedad desde la problemática de género (MG), Rosario, Argentina. ISSN, 2545-6504 http://zonafranca.unr.edu.ar/index.php/ZonaFrancal Número 28 (2020). Página 387 
Taking a feminist look at Argentine literature implies retracing a path built on a dynamic of readings and re-appropriations, of deviated citations, of silences and some oversights. It is already a fact that feminism has occupied a leading role in a present where literature and women writers occupy the streets and public spaces. In this scenario, emerges this text with a tendency to miniaturization. It serves the purpose of asking once again who writes the canon, understood as selective and hierarchy-making system. Cecilia Szperling's "autobiographical fable", La máquina de proyectar sueños (2006), is a breviary of childhood vignettes, rooted in a tradition including several examples, but mainly Norah Lange's Cuadernos de infancia (1937). This analysis concentrates on two elements: on the one hand, the construction of a counter-canonical "library" from which other minority voices are legitimized (women and feminized subjects, children); on the other, the use of audiovisual devices as an inseparable element for the construction of both individual and collective memory.

Keywords: argentine literature, childhood, canon, feminism, Cecilia Szperling.

-una imagen que despierta la memoria, una memoria que despierta la imagenLeonor Arfuch, "Memoria e imagen"

\section{Una chica moderna}

Hay algo del orden de la distracción en una novela que se anuncia desde la ambigüedad ya en su mismo título al auto-designarse como una "fábula autobiográfica", y que nos sitúa en un ámbito doblemente minorizado: la infancia, lo femenino. La tapa del libro de Cecilia Szperling no es plana; se abre como un retablo en diálogo con las artes plásticas y con la música nacional. Por un lado, el título dialoga con el rock al parafrasear el nombre del grupo La Máquina de Hacer Pájaros'; por el otro, la imagen nos interpela con los rostros de esas dos niñas materializadas por Flavia Da Rin, cuyo trabajo de por sí combina la fotografía con lo pictórico, en un sistema de transmutaciones del que no está ajena tampoco la

I La Máquina de Hacer Pájaros fue un grupo de rock sinfónico que formó Charly García tras la disolución de Sui Generis junto con Oscar Moro, Carlos Cutaia, Gustavo Bazterrica y José Luis Fernández. Fue una experiencia de corta vida y que editó dos discos: La Máquina de Hacer Pájaros en 1976 y Películas en 1977. Véase: https://rock.com.ar/artistas/361

Revista Zona Franca- Centro de estudios interdisciplinario sobre las mujeres (CEIM)- Maestría poder y sociedad desde la problemática de género (MG), Rosario, Argentina. ISSN, 2545-6504 http://zonafranca.unr.edu.ar/index.php/ZonaFrancal Número 28 (2020). 
historieta." Las niñas de la tapa no nos miran, sino que dirigen la mirada hacia los márgenes (izquierdo y derecho, superior e inferior) y producen mediante esa gestualidad el efecto del fuera de campo. No solo hay dinamismo en sus rizos, sino en esos desvíos de la mirada. La pose de la chica con pelo más claro aparece centrada; su expresión, no obstante, la muestra inquieta o atemorizada, atraída por la visión de algo que seduce y repele a la vez. Por el contrario, la chica de pelo oscuro exhibe una actitud alerta y un tanto aviesa. Si la primera abre bien los ojos y nos invita a privilegiar lo visual, la segunda parece estar orientándonos a la escucha.

El siguiente análisis va a seguir un derrotero que comienza poniendo en diálogo el texto de Cecilia Szperling con otra escritora que -de manera algo imprevista- emerge como su "precursora": Norah Lange a partir de su texto Cuadernos de infancia (1937). En ambas autoras hay un impulso autobiográfico que elige un tipo original de senda: la de los desvíos y fluctuaciones de la ficción. Facetar la narración del yo mediante la fragmentación de las viñetas, permite desmontar los mecanismos que se ponen en funcionamiento en todo intento de contar la propia historia. Logran exhibir, de ese modo, la ilusión del relato biográfico. El montaje, como entendía Aby Warburg, es la estrategia que sirve para hacer emerger todo aquello que se produce en el encuentro más o menos fortuito de lo heterogéneo."I Genera el saber propio de las constelaciones, a partir de conexiones impensadas y de encuentros afortunados. Estas dos obras de escritoras mujeres, conscientes en ambos casos de los recursos que ofrecen las tecnologías visuales (aunque sea en dos momentos distintos de su desarrollo), aplican el sistema de montaje para la

\footnotetext{
"Flavia Da Rin produce una obra en la que se cruzan las innovaciones tecnológicas con cuestiones vinculadas con la pregunta por la identidad. Mediante la manipulación y el retoque digital de fotografías en las que ella es el objeto fotografiado trabaja la tensión entre una configuración propia de la personalidad y aquello que la acucia desde el mundo exterior. Véase la presentación de la exposición que le dedicó el Museo Moderno en 2019, "Flavia Da Rin ¿quién es esa chica?", https://www.museomoderno.org/es/exposiciones/flavia-da-rin-quien-es-esa-chica.

III Es a través de la obra del historiador del arte George Didi-Huberman que se produce la presente entrada a las ideas de Aby Warburg para su noción de montaje y constelaciones, como formas de conocimiento. Didi-Huberman lo desarrolla particularmente en su libro Atlas ou le gai savoir inquiet (2011), tercer volumen de la trilogía L'oeil de l'histoire. El "atlas" como principio constructivo se sostiene en la idea de que las imágenes, ensambladas de una cierta manera, nos ofrecen la posibilidad de una relectura del mundo (20).
}

Revista Zona Franca- Centro de estudios interdisciplinario sobre las mujeres (CEIM)- Maestría poder y sociedad desde la problemática de género (MG), Rosario, Argentina. ISSN, 2545-6504 http://zonafranca.unr.edu.ar/index.php/ZonaFranca| Número 28 (2020). 
escritura. La distancia temporal entre uno y otro texto $(1937,2016)$, no impide ver la continuidad de una propuesta, el trazado de una línea que resulta elocuente en términos del desarmado del canon y de sus prerrogativas: quién toma la palabra, cómo lo hace, a quién se dirige. Hay en estos textos un deseo de miniaturización que diversifica los relatos que una nación se cuenta a sí misma.

El "aniñamiento" con el que se pretendía ubicar en ciertos márgenes preciosistas a una escritora como Norah Lange, se devela como voz insidiosa que sigue hablando casi ochenta años más tarde. No resulta tan inocente, por lo tanto, el acto de mover la mirada de lugar; de jugar con ella para trabajar sobre esos espacios inciertos que surgen cuando se corre el punto de mira de una focalización obsesionada con lo trascendente. Szperling pertenece a una generación que creció con las tecnologías visuales y que, a la manera del ciborg, ya piensa en términos maquínicos. Pero además es representante de un colectivo que se asume feminista en esta primera parte ya tan convulsionada del siglo. Esto implica un cambio considerable con respecto a su antecesora en las letras. Como impulsora de, entre otras iniciativas, la plataforma Nosotras Proponemos para promover la crítica del sexismo en las prácticas del campo literario argentino, asume un rol no solo autoconsciente, sino activo, beligerante, movido por la urgencia. ${ }^{\mathrm{IV}}$ Este presente en el que las pibas ya están en la calle, con todo lo que eso significa, es elocuente de un largo camino recorrido que esta autora no hizo sola, sino en preclara compañía, entre quienes sobresalen - por supuesto- Virginia Woolf y Simone de Beauvoir. Pero también, como se verá, hay en el texto una reivindicación de la biblioteca de infancia que ha formado a las mujeres a lo largo de varias décadas y que junta en sus

IV La iniciativa se concreta en abril del 2018 y reúne las ideas de un colectivo de más de 250 escritoras. Además de reivindicar a la literatura como un trabajo, lo mueve la necesidad de desmontar los estereotipos sexistas y las prácticas discriminatorias. Lo hace desde un feminismo que se concibe como transgeneracional y transdisciplinario, orientado a generar una cultura de la solidaridad y opuesto a la idea de "canon". Los diez puntos de Nosotras proponemos literatura pueden verse en https://www.lavaca.org/notas/nosotras-proponemos-literatura-13-puntos-que-proponen-unapractica-feminista-de-la-escritura/

Revista Zona Franca- Centro de estudios interdisciplinario sobre las mujeres (CEIM)- Maestría poder y sociedad desde la problemática de género (MG), Rosario, Argentina. ISSN, 2545-6504 http://zonafranca.unr.edu.ar/index.php/ZonaFrancal Número 28 (2020). 
anaqueles a Tolstoi o Poe con Louisa May Alcott. No es nada nuevo, pero vale la pena recalcarlo: el feminismo actual no le teme al glitter. ${ }^{\vee}$

\section{Juegos de simetrías}

El texto de Szperling se ubica con comodidad dentro de una tradición latinoamericana de relatos de infancia consignada por Sylvia Molloy en su conocido ensayo Acto de presencia. La escritura autobiográfica en Hispanoamérica (1991). Con cierta transparencia es posible vislumbrar el diálogo de esta "fábula autobiográfica" de Szperling con los Cuadernos de infancia (1937) de Norah Lange, texto al que Molloy le dedica una particular atención en un gesto en el que pone en acto la construcción de sus propios "precursores". Algo de esta estructura fragmentaria será retomado en varias de sus obras, pero la traza de Lange se trasluce principalmente en Varia imaginación (2003) en el que la infancia ocupa buena parte de la escena. ${ }^{\mathrm{V}}$ Textos que se despliegan como una serpentina de postales, no solo evocan una visualidad a partir de evidentes dispositivos ópticos o tecnológicos, sino que lo hacen para reflexionar sobre la memoria, sus modos de configuración y su funcionamiento. VII De ahí que el entramado sea profundamente afectivo y no una mera crónica de tiempos pasados.

Sylvia Molloy, al pensar en la autobiografía en tanto que re-presentación, pone el acento en la articulación más que en los sucesos narrados (1996: 16). Por eso es que subraya el interés de la lectura en el texto no escrito: la pulsión, el fragmento, el rastro. Molloy hacía notar sobre el texto de Lange su carácter de espacio escriturario en el que la autora experimentaba no solo con las posibilidades del

\footnotetext{
$\checkmark$ Para una descripción de las nuevas generaciones, sus ideas y sus estéticas renovadoras, véase la crónica que escribió Luciana Peker, La revolución de las hijas (2019).

VI José Amícola ya lo advertía en su libro Autobiografía como autofiguración (2007) en el capítulo que le dedica a Lange cuando llamaba a Molloy como "su mejor sucesora" (150) para un texto como Varia imaginación, construido según "principios similares". Yo retomo esta vinculación en el capítulo quinto, "Álbum de familia", de mi libro Topografías del estallido (2018).

VII A propósito de estas cuestiones formales en Lange, véase para el tema de los recursos visuales a Sierra (2005) y para la cuestión de la memoria a Carli (2011).
}

Revista Zona Franca- Centro de estudios interdisciplinario sobre las mujeres (CEIM)- Maestría poder y sociedad desde la problemática de género (MG), Rosario, Argentina. ISSN, 2545-6504 http://zonafranca.unr.edu.ar/index.php/ZonaFrancal Número 28 (2020). 
lenguaje (enmarcadas dentro de las convenciones del ultraísmo y del surrealismo), sino con su propio posicionamiento dentro del campo literario, por lo que la reivindicación de la infancia en estos "cuadernos" tenía más que ver con razones epistemológicas. Nada había de idílico en ese mundo de la niñez, sino que Lange según Molloy- lo exploraba como una "reserva de posibilidades dinámicas" (172) que se vinculaba con la búsqueda de un espacio enunciativo original y propio. En un texto posterior, Molloy reafirmará estas apreciaciones sistematizándolas de la siguiente manera: "El aparentemente apacible reino infantil en que se basaba el libro disimulaba el hecho de que el texto convertía el recuerdo de vida en investigación literaria, el lugar de la niñez en laboratorio a menudo inquietante" (2005: 21).

La "fábula autobiográfica" de Szperling sugiere algunas de estas ideas. El "laboratorio" aparece mentado como el lugar de trabajo de Madre. La experimentación de la niña protagonista, sin embargo, no se centra tanto en la adquisición de un lenguaje como en la persecución de un proyecto personal que deviene en el trabajo con la herramienta de la escritura, como se aprecia en la escena final que nos muestra a la mujer en el acto de escribir el libro que estamos leyendo. Por otro lado, el proceso de la escritura es narrado de manera algo distinta por la propia Szperling en entrevistas, cuando explica que en realidad lo pensó como una serie de piezas para leer junto con la cantante Paula Maffia. En su origen, entonces, era un texto vinculado con la teatralidad y la oralidad: "tuvo primero escenario y después tuvo página. [...] Quizás es un libro un poco performático" (Méndez, 2016), afirma su autora.

El texto de Szperling replica la estructura algo fragmentaria que configura la narración dispersa de memorias de infancia y que permite hablar del formato de "viñetas", si bien -a diferencia de Lange- ella le da un ordenamiento a través de una serie de apartados que llevan un título alusivo en cada caso. Se percibe un cierto movimiento zigzagueante que no impide ver la progresión temporal demarcando el camino de la primera infancia hacia la adolescencia. El recurso de lo visual, como se verá, está puesto al servicio de esa reflexión sobre la memoria a

Revista Zona Franca- Centro de estudios interdisciplinario sobre las mujeres (CEIM)- Maestría poder y sociedad desde la problemática de género (MG), Rosario, Argentina. ISSN, 2545-6504 http://zonafranca.unr.edu.ar/index.php/ZonaFranca| Número 28 (2020). 
la que se refería Molloy, y a la que se piensa como una instancia difícil de aprehender porque está poniendo en acto diversas temporalidades: una mirada instalada en el presente que desea recrear focalizaciones en diversos puntos del pasado. Los recursos que utilizará Szperling difieren en cuanto a la tecnología elegida (el cine más que la fotografía), pero no deja de colocar el acento en lo visual. Lo llamativo, por otro lado, son ciertos elementos afectivos que conforman el entramado textual, así como la figura de infancia que emerge como resultado de estas operaciones y que coinciden con el texto de Lange. En cuanto a lo primero, la muerte del padre abría Cuadernos de infancia y marcaba esas memorias, habilitando un sistema de subterfugios: era una especie de "trampa" que contaminaba los juegos de este ramillete de hermanas. VIII Con respecto a lo segundo, la cuestión de la performance, que fuera leída por la crítica como una puesta en abismo de la actuación "ultraísta" de Lange en los círculos literarios de su tiempo, permite ser reconsiderada desde una perspectiva feminista como un cuestionamiento -también soslayado- a las prescripciones de género (Punte, 2016).

Las coincidencias entre el texto de Szperling y el de Lange resultan, por momentos, deslumbrantes. De manera literal: funcionan como un flash que nos distrae e impide la mirada. ¿Será el recurso de una chica que pasa su adolescencia en la transición de los años sesenta a los setenta, entre un asomante "glam" y la travesía por una época oscura? Lo cierto es que una primera mención ya nos coloca en posición de alerta: la referencia a las "tres ventanas" desde las que se asoma esta infancia. Lange introducía el tema ya en el tercer fragmento: "Tres ventanas dan sobre mi niñez" (2005: 379). A través suyo, se hacía referencia a un sistema narrativo de múltiples entradas que pensaba las relaciones intrafamiliares, sus pequeñas jerarquías y las rendijas que permitían saltearse las consecuentes

\footnotetext{
VIII María Elena Legaz sostiene que la muerte es incorporada en el texto de Lange mediante la mirada de la infancia y de lo doméstico como algo natural o, al menos, aceptado como "las sombras del sótano y los ruidos misteriosos de la noche" (2010: 81). Sin embargo, agrega, las muertes prematuras como la del padre necesitan ser aprehendidas a través del ejercicio de la imaginación, porque significan una privación, dejan un vacío, configurando así la "zona oculta de la existencia" (82). Por eso, concluye, la muerte, junto con el miedo y el misterio, son los rasgos de la atmósfera que permea toda esta autobiografía.
}

Revista Zona Franca- Centro de estudios interdisciplinario sobre las mujeres (CEIM)- Maestría poder y sociedad desde la problemática de género (MG), Rosario, Argentina. ISSN, 2545-6504 http://zonafranca.unr.edu.ar/index.php/ZonaFrancal Número 28 (2020). 
exclusiones. IX Szperling retoma este guante que da vuelta la ecuación del mirar-ser mirado y que otorga una forma de poder a la niña en su rol de "mirona". Al principio de su texto la narradora nos informa que "Hay tres ventanas en nuestra habitación, una para cada una" (2016: 13). Estas tres ventanas son reales, pero la descripción hace pensar en tres nichos en cada uno de los cuales las hermanas se ubican para resultar, de ese modo, enmarcadas: “¿Nos verán desde la calle? ¿Alguien mirará hacia arriba, al primer piso de esa casa de frente de piedra, y verá a tres niñas tras los vidrios?" (13). Más allá de la coincidencia formal, el tema que introduce el fragmento (NOCHE 2) es el de los temores infantes (un tema omnipresente en el texto de Lange). La protagonista de La máquina... nos cuenta de sus insomnios que la llevan a deambular por la casa a oscuras, entre la curiosidad por las formas diversas que emergen de la ausencia de luz y la sensación espectral de circular por un mundo aletargado. Mientras el resto de la familia duerme y la ignora, ella no sabe si sentir terror o atracción por ese momento solitario que le permite explorar otra faceta de lo cotidiano.

A semejanza del texto de Lange, la "fábula autobiográfica" de Szperling se ve atravesada por el acontecimiento ominoso de la muerte de Padre. Una variante fundamental radica en que la muerte no está al principio, como en Cuadernos de infancia, sino al final: no es leída como la causa de la precariedad económica que irá desgranando Lange en su texto y que en su caso es determinante para la propia autobiografía. En el texto de Szperling el acento está puesto lisa y llanamente en la cuestión de la vulnerabilidad a las que nos somete la experiencia de la muerte próxima. ${ }^{X}$ Se puede retomar lo que proponía María Elena Legaz para el de Lange

IX La referencia a las "ventanas" tenía que ver con la idea de abordar su mundo cotidiano desde una perspectiva que se le antojaba como una forma de mirilla. Una daba hacia el universo del padre, con su escritorio intimidante y atractivo a la vez; otra hacia el ámbito acogedor de la madre y su cuarto de costura, "impregnado de ternura" (2005: 380); la tercera correspondía a la hermana mayor, Irene, que se le hacía siempre misteriosa porque de allí venían "las más grandes sorpresas" (381). Más que ventanas literales, se trata de pequeñas películas como las de los comienzos del cinematógrafo, aquellas que producían los hermanos Lumière y que dan origen a un género dedicado íntegramente a la infancia, un archivo casi perdido hoy (Lebeau 2008).

${ }^{x}$ Como se sabe, es la filósofa Judith Butler quien ahonda en la condición existencial de vulnerabilidad develada por el duelo, a partir de la idea de es la pérdida aquello que nos hace conscientes de no

Revista Zona Franca- Centro de estudios interdisciplinario sobre las mujeres (CEIM)- Maestría poder y sociedad desde la problemática de género (MG), Rosario, Argentina. ISSN, 2545-6504 http://zonafranca.unr.edu.ar/index.php/ZonaFrancal Número 28 (2020). 
(algo que ya fue mencionado en la nota 4): la idea de que una muerte temprana abre una hendidura para los deudos que impide "acercarse a los enigmas que cada vida preserva para sí y que constituyen la zona oculta de la existencia” (Legaz, 2010: 82). En cierto modo coincide con el texto de Lange en mostrar con sutileza la existencia volátil de los vínculos, aún aquellos considerados más estables y duraderos. Esta constatación se verá reforzada hacia el final en la novela de Szperling.

Un matiz que demarca la distancia temporal entre ambos textos es que, a pesar de la mayúscula con la que la voz narradora se refiere a la figura paterna y la consiguiente despersonalización a la que lo somete el rol dentro de la estructura familiar, transmite la imagen de un padre cercano y por momentos cómplice, de alguien que se aleja por la circunstancia no elegida que le imponen su enfermedad y temprana muerte. La narración que se extiende más o menos desde los cuatro hasta los catorce años de la protagonista va recabando los pequeños indicios de una crónica que se le antoja un tanto anunciada. El personaje de Padre se presenta desde el inicio del relato como alguien enfermizo, con sus constantes dolores de espalda, una intervención quirúrgica, un retiro laboral temprano. Contrasta con la vitalidad y la potencia de Madre. Ambos son profesionales y sus respectivos ámbitos laborales atraen a la niña, que se deja guiar por ellos como si fueran lugares exóticos a los que va de excursión: la oficina de Padre; el laboratorio en el hospital en donde trabaja Madre. Las "ventanas" de esta niña la conducen al mundo exterior, al espacio que se despliega más allá de los muros del hogar. Todas las anécdotas que tienen por protagonista a Padre convergen en la escena final de la niña escapando ante su muerte que se le hace obscena, algo que no puede contemplar y que la obliga no solo a desviar el rostro, sino a sustraer el cuerpo.

tener el control y que nos conduce a la aceptación del cambio. El duelo nos coloca frente a una experiencia de transformación que no por fuerza podemos elegir, sino que nos obliga a enfrentarnos con lo enigmático. Expone el lazo entre el yo y el tú, ese vínculo cuya pérdida nos desorienta momentáneamente con respecto a lo que somos. El duelo nos enseña la sujeción a la que nos somete nuestra relación con los otros en formas que no siempre podemos explicar (2009: 45-49).

Revista Zona Franca- Centro de estudios interdisciplinario sobre las mujeres (CEIM)- Maestría poder y sociedad desde la problemática de género (MG), Rosario, Argentina. ISSN, 2545-6504 http://zonafranca.unr.edu.ar/index.php/ZonaFranca| Número 28 (2020). 
El sistema de desdoblamiento de la mirada funciona aquí a partir de una testigo, su amiga Mushka, a la que ella olvida para reencontrar veinte años más tarde. Mushka le trae nuevamente la escena de su explosión en llanto y de la huida a casa de los vecinos. Resulta sugerente en la vinculación con el texto de Lange este momento hacia el final del libro en el que la chica sale corriendo, atraviesa el "jardín salvaje" y salta el muro en dirección a la casa de la familia vecina con cuyos cuatro hijos compartían edades y juegos. Cuando pueda recuperar esta escena que fuera reprimida, la protagonista logrará reflexionar sobre dicho acto como una performance dolorosa en la que escenifica la rabia ante la pérdida. Se hace explícito aquí el comienzo de un trabajo de duelo cuya concreción es reconocida muchos años más tarde mediante otro acto: la escritura del texto que tenemos entre manos. En Cuadernos de infancia, un momento semejante que aunaba la furia con la performance también cerraba el libro. Allí, la adolescente de catorce años se paraba sobre los techos de su casa y se dedicaba a insultar a los vecinos disfrazada con un poncho y un chambergo que habían pertenecido al padre. Esta escena, que fue leída como un adelanto de la performance ultraísta de Norah Lange mediante sus discursos en los que homenajeaba a sus "congéneres" tras la búsqueda incipiente de una voz propia, aparece como un ritual de pasaje que demarca el fin de la infancia. En el texto de Szperling, funciona como una perilla que activa la máquina, que acciona tanto a la moviola como a la escritura.

\section{La biblioteca femenina}

Una vez que convenimos, como hace Molloy, con la idea de que el relato autobiográfico no se basa en una "realidad", sino en la vida en tanto que "relato de lo que nos contamos a nosotros mismos, como sujetos, a través de la rememoración" (1996: 16), se trata de poner el foco en la lectura de esta fábula en lo que Molloy define como las "formas culturales". Así designa a "los fragmentos de textos verdaderos a los que recurre el autobiógrafo para dar forma a lo que almacenó en la memoria" (16). El gesto del autobiógrafo en Hispanoamérica según

Revista Zona Franca- Centro de estudios interdisciplinario sobre las mujeres (CEIM)- Maestría poder y sociedad desde la problemática de género (MG), Rosario, Argentina. ISSN, 2545-6504 http://zonafranca.unr.edu.ar/index.php/ZonaFranca| Número 28 (2020). 
Molloy se caracterizaba por echar mano de un archivo europeo en vistas a forjar su imagen a través de esos fragmentos textuales. Pero, en el curso de ese proceso, el material resultaba alterado, constituyendo "otra lectura" (16, cursivas en el original). En la "escena de lectura", una escena "desviada" dice en este punto Molloy, es que se manifiesta la diferencia del autobiógrafo. Me interesa retomar la idea para leer el texto de Szperling y de su repositorio cultural, pero ya no como un archivo de textos legitimados en lo que respecta a la cultura hegemónica (algo que, por cierto, está actuando en su narración), sino desde un archivo de género (en el sentido de gender). Es así como la idea de desviación o torsión adquiere otras connotaciones en términos de legitimidad.

Las alusiones al mundo de la literatura no abundan en el libro, pero son elocuentes. Sirven al sistema de auto-percepción que, como clase educada, esta familia construye sobre sí misma. La madre recurre a la novela de Beatriz Guido La mano en la trampa (1961) para referirse a unos vecinos que les resultan misteriosos; a los que ven a la distancia como tres personas mayores hoscas y descoloridas. Lo habitantes de esa "casa vecina decrépita y detenida en el tiempo" (46) no dejan traslucir los lazos que los unen como familia hasta que aparece una nieta adolescente de catorce años, Nikita, que entabla contacto con la protagonista y logra deslumbrarla con su desfachatez. No resulta muy difícil, ya que la protagonista tiene nueve años y reacciona de inmediato ante esta chica "hermosa, vivaz y maquillada" (46) cuya aparición le produce un estallido de felicidad.

Por otro lado, no se hacen demasiadas menciones a las lecturas infantiles de estas tres hermanas, con la excepción del cuento tradicional "Hansel y Gretel", parte del repertorio usual de Goya, la empleada, junto con las canciones que canta y que a la niña de tres años le resultan tristes. Esas canciones destinadas a hacerla dormir, "son como puñales clavándose en mi corazón" (24) porque narran historias de amores frustrados. Algunas ficciones atraviesan la trama por conductos subterráneos. Se ve en un comentario que hace la niña a los cuatro años cuando se refiere a la manera en que debió internalizar el mandato de no molestar a los que

Revista Zona Franca- Centro de estudios interdisciplinario sobre las mujeres (CEIM)- Maestría poder y sociedad desde la problemática de género (MG), Rosario, Argentina. ISSN, 2545-6504 http://zonafranca.unr.edu.ar/index.php/ZonaFranca| Número 28 (2020). 
duermen. Así es como aparece Scherezade para referirse a su estrategia de narrar historias con el objetivo de distraer a las hermanas y evitar así que se duerman. En oposición, apela a la Bella Durmiente para definir a las dos hermanas quienes, a diferencia de ella, logran dormirse. La protagonista declara luego que en esa casa "Una ley prohíbe interrumpir el sueño. En casa podrían decapitarme" (21), frase que se repite dos veces (en la NOCHE 6 y la NOCHE 7) y que evoca al personaje de la Reina de Corazones de Alicia en el País de las Maravillas, pero además delata el mecanismo mediante el que los sujetos infantes aprehenden la ley y sus límites.

Con respecto a una "escena de lectura" literal, la narradora la adjudica a su hermana mayor en el fragmento "Victoria lee" (42-45). Allí muestra a Victoria, de doce años, dedicada a leer literatura infantil de una manera tan absorbente como inquietante. Cuando Victoria lee, nos dice la protagonista, parece estar hipnotizada o en trance. Lee "esas sagas de niños anticuados en colegios pupilos" (42) que narran historias de infancias sufrientes y abnegadas. ${ }^{X I}$ Ella, por su parte, prefiere dedicarse al entrenamiento con la lengua, sobre todo con las "palabras de ataque". Lo hace porque descubre el efecto que produce la "palabra hiriente" para llamar la atención y como maniobra defensiva: "Nadie soporta la palabra como cuchillo" (42). Por el contrario, la palabra que acaricia tiende a producir un estado letárgico, "nos duerme" (42). Este tipo de palabras adquiere a sus ojos un carácter mágico, porque si bien ellas "activan el veneno en el oído del que las escucha" (42), salen de la boca con liviandad.

El espacio en el que elige moverse la narradora protagonista se ubica, de acuerdo con la posición que le tocó en suerte, en un punto medio entre la introspección de la hermana mayor y la destreza con el cuerpo que es la prerrogativa de Inés, la hermana menor. ${ }^{X I I}$ Las tres hermanas coinciden en el gusto

\footnotetext{
XI No está dicho de modo explícito, pero hace referencias a varios textos que pueden ser Heidi, Mujercitas o las novelas de Dickens.

XII De hecho, este es el fragmento en donde se introducen los nombres de las hermanas, Victoria e Inés. Hasta ese momento eran mencionadas por su posición en el sistema de edad: Mayor y Menor. A los padres se los llamará en todo momento de acuerdo con su función: Madre y Padre.
}

Revista Zona Franca- Centro de estudios interdisciplinario sobre las mujeres (CEIM)- Maestría poder y sociedad desde la problemática de género (MG), Rosario, Argentina. ISSN, 2545-6504 http://zonafranca.unr.edu.ar/index.php/ZonaFranca| Número 28 (2020). 
por la teatralidad: "Suena la consagración de la primavera, por ejemplo. Y nos sentimos en un gigantesco escenario" (43). ${ }^{\mathrm{XIII}} \mathrm{A}$ las tres les gusta bailar, armar obras de teatro caseras, jugar a la actuación. Con Inés comparten "la fantasía del teatro privado" (44). .IV Ambas juegan a ser directoras teatrales: hacen las luces, diseñan los desplazamientos, dan directivas de entrada y salida de un escenario imaginado: "ahora entrá, ahora te ovillás como un bebé, ahora salto en alto, ahora saltás en largo" (44). La teatralidad permite hacer confluir lo que cada una de ellas desempeña con mayor destreza: la textualidad, el ejercicio de la palabra, la plasticidad del cuerpo.

Esta idea de las niñas y la teatralidad encuentra sustento en aquello que Seth Lerer define a partir de la metáfora de los "dioramas del deseo" (2008: 241). En su recorrido sobre la historia de la literatura infantil (que se extiende desde Esopo y las fábulas hasta Harry Potter), Lerer aborda la figura de las niñas en tanto que lectoras, pero también como personajes de ficciones clásicas. Allí constata que las niñas han sido configuradas como estando siempre ubicadas en un escenario: ser mujer es una permanente representación. ${ }^{X V}$ Esta actitud psíquica y corporal cristaliza en una forma de existencia que no se desvanece, sino que va adquiriendo otras modulaciones. Comienza en el seno del hogar y en una educación para la domesticidad transmitida en gran parte a través de las lecturas de infancia, y que adquiere derroteros diferenciados en función del género: mientras que en los niños se incita el deseo de aventuras, a las niñas se las entrena para ser buenas administradoras de las energías domésticas. De ahí la idea de que el deseo se organiza en términos espaciales como un "diorama": acotado, escénico, alegorizante. A las niñas se les estimula el gesto de ponerse en escena, lo que las

XIII En un momento usará como referencia literaria a Chejov para referirse a su familia y a su "Gran Casa", que se le aparece como un espacio lleno de conflictos estilo Chejov.

XIV Para la cuestión de la teatralidad en relación con lo autobiográfico, véase la entrevista que le hace Silvina Friera (2016) en donde la autora enfatiza haber crecido en una casa que era como un teatro, y en cómo este libro abreva en la dramaturgia y lo teatral.

${ }^{X V}$ Esta idea ya había sido desarrollada por la psicóloga feminista Joan Rivière en su concepto de "mascarada" femenina, que designa un ideal de feminidad nunca logrado, cuyo alcance será luego ampliado y diversificado por la noción de performance de Judith Butler (Berger, 2016: 40).

Revista Zona Franca- Centro de estudios interdisciplinario sobre las mujeres (CEIM)- Maestría poder y sociedad desde la problemática de género (MG), Rosario, Argentina. ISSN, 2545-6504 http://zonafranca.unr.edu.ar/index.php/ZonaFranca| Número 28 (2020). 
coloca en una tensión entre vivir para la delectación de (la mirada de) los otros o el encuentro de una virtud íntima que puede desdoblarse en la devoción hacia la familia o hacia el estudio (228). Pocos textos lo organizan narrativamente de mejor manera que la novela de Louise May Alcott, Mujercitas, devorada por generaciones de niñas a lo largo de más de un siglo, ${ }^{\mathrm{XVI}}$ a través de su versión literaria y de la serie que se arma desde allí, así como de las películas.

Otra escena significativa de lectura es la que tiene lugar en las sierras, cuando están de vacaciones en un hotel que provoca terror en la protagonista. XVII La niña debe quedarse un día en cama como consecuencia de una insolación. Para su enorme placer, Madre dedica ese día a cuidarla. Comienza leyéndole un texto de literatura infantil, Puck, estrella de cine, pero luego pasa a recitarle poesía. ${ }^{\mathrm{XVII}} \mathrm{La}$ madre "declamadora" no es una novedad para la niña. El arte de declamar formaba parte de la educación de esta madre que recurría a él cuando quería entretener a las visitas y lucirse ante ellas, algo que la niña recuerda no sin vergüenza. En la situación tan exclusiva para la protagonista de monopolizar la atención de Madre, es testigo de cómo esta se transforma ante sus ojos en una especie de diva del cine de Hollywood. La anécdota de la madre declamadora concluye cuando al día siguiente sea la hija quien la imite, recitando los mismos textos acompañados de su

XVI Lerer comienza citando como ejemplo el caso del personaje de Hermione en Harry Potter, tanto en el libro como en el film. Luego pasa a analizar junto con Mujercitas (1872) otras dos novelas emblemáticas: Anne de los Tejados Verdes (1877) de la canadiense Lucy Maud Montgomery, y El Jardín secreto (1910) escrito por Frances H. Burnett. Los dos primeros son ejemplos muy claros de la cuestión de la teatralidad unida a la identidad de la niña, y de su tensión con la posibilidad de ejercer la literatura.

$\mathrm{XVII}$ Las historias que leen estas chicas sirven para moldear experiencias, aunque parezcan muy ajenos los contextos. Se ve en ciertas fantasías, por ejemplo, en cómo la protagonista percibe los espacios desde un modo "gótico": el Hospital de Niños le hace pensar en los internados de niñas del siglo XIX (62) o el hotel en donde hacen vacaciones en las sierras se le antoja un asilo psiquiátrico, una casa embrujada, una cárcel secreta (65), por lo que lo bautiza como "Hotel Clínica".

XVIII Puck es el personaje de una serie de novelas de literatura infantil juvenil de origen danés, pensada para chicas. Sus autores, Knud Meister y Carlo Andersen, escribían con un pseudónimo femenino (Lisbeth Werner). La serie se publicó entre 1943 y 1962. En español apareció entre 1969 y 1988, llegando a incluir veintinueve títulos. La saga se desarrolla durante siete años de la vida de esta adolescente danesa apodada Puck (su nombre es Bente Winther), en la que se narran sus diversas aventuras durante los años pasados en un internado a mediados de la década de los cincuenta.

Revista Zona Franca- Centro de estudios interdisciplinario sobre las mujeres (CEIM)- Maestría poder y sociedad desde la problemática de género (MG), Rosario, Argentina. ISSN, 2545-6504 http://zonafranca.unr.edu.ar/index.php/ZonaFranca| Número 28 (2020). 
correspondiente gesticulación. La rememoración del acto declamatorio revela las distintas temporalidades que se concentran en él: las reuniones familiares en los que Madre se convierte por un momento en el centro; el uso que la madre hace de su actuación para construir una intimidad cómplice; el reconocimiento por parte de la hija de esa complicidad.

La entrada en la adolescencia a los trece años supone un cuarto para ella sola y la apertura de un mundo de lecturas ya establecido en el canon adulto: los cuentos de Edgar A. Poe, la novela Anna Karenina, el "Tlön, Uqbar, Orbis Tertius" de Borges. Es la novela de Tolstoi la que ella considera clave para su educación sentimental. Se compenetra totalmente con esta lectura que, según sus palabras, la "arrastra a una zona de sufrimiento nueva y desesperante" (110). La novela Anna Karenina la convence de que no hay que dejarse caer en la pasión amorosa y que lo mejor es no enamorarse. ${ }^{X I X}$ Se ve a sí misma emergiendo renovada como una "niña reptil, acorazada de escamas" (108), munida de "varias corazas, como una gladiadora o una guerrera". Concentra su pasión en el disciplinamiento del cuerpo mediante las clases de danza, un cuerpo que todavía no le genera problemas y al que ve como una pieza para llevar un vestido puesto. Su atención está dirigida, más que nada, a dilucidar las falsedades del mundo, enseñanza que cree haber recibido de Padre y que la lleva a sostener que "Lo cotidiano se transforma en un decorado berreta" (112).

Ese par de años de la adolescencia se ven tramados desde una serie de rutinas que incluyen las clases de danza, la Escuela Nueva a la que se cambia para hacer el secundario, y los paseos con los amigos que la introducen en nuevos gustos musicales y la acompañan en la flânerie por la ciudad. Su mundo empieza a

XIX Esta seguridad se resquebraja un poco cuando su amigo $A$ (tras quien se esconde quien fuera su compañero en la escuela, Andrés Calamaro) compone una canción que la conmueve: No te enamores nunca. El tema de cómo ella fue la inspiradora de la canción estuvo circulando en los medios gráficos y radiales a partir de la "confesión" que hace Calamaro de este episodio y que fue confirmado por Szperling. Lo hace, por ejemplo, en la entrevista que le realizan en Infocielo Albino Aguirre y Jorge Perroni. Se puede escuchar en: https://infocielo.com/nota/119253/escucha-a-ceciliaszperling-la-mujer-que-inspiro-a-calamaro-en-mil-horas/

Revista Zona Franca- Centro de estudios interdisciplinario sobre las mujeres (CEIM)- Maestría poder y sociedad desde la problemática de género (MG), Rosario, Argentina. ISSN, 2545-6504 http://zonafranca.unr.edu.ar/index.php/ZonaFranca| Número 28 (2020). 
oscilar entre dos amigos que representan idiosincrasias opuestas. Por un lado, está $A$, el Chico Punk ruidoso y desenfrenado, que toca música en una banda y declara estar enamorado de ella ante quien quiera escucharlo. Amor que, por otro lado, ella no desea corresponder. Su otro amigo es Jota, quien responde mejor al modelo del "artista romántico", tranquilo y suave. Si A es como un oso en la selva, Jota es como una gacela. A está siempre en ebullición; Jota es "imperceptible". Como para dirimir este falso empate, aparece Félix. Es un muchacho de veinticinco años que le abre otra perspectiva porque trabaja en una agencia de publicidad, vive en su propio departamento, se interesa por el arte y el diseño. Sin embargo, la protagonista persiste en su actitud de mantenerse equidistante de estos tres chicos que la cortejan, porque prefiere ver todo desde afuera. El mundo se le antoja como "un bosque lleno de especies que contiene muchas cosas, pero yo no me entrego a ninguna" (122). Lo que para ella constituye una certeza es el hecho de que los tres chicos le sirven para establecer distintos puntos de contacto consigo misma, por lo tanto, para desplegar y auscultar diversas facetas de sí. En ese sentido, la biblioteca no existe como espacio cerrado, sino que se activa en el diálogo con estos interlocutores más o menos atentos, más o menos alertados de cómo resultan ellos mismos leídos por la chica.

\section{Como en una película}

La alusión a lo visual para pensar el funcionamiento de la memoria y su transposición al sistema textual comienza ya desde el título: La máquina de proyectar sueños. Esta mención nos predispone como lectores no solo para situarnos en un determinado contexto social y de época, sino también para reconocer el formato que la narración asume como propio al revelarlo en el movimiento de trasladar materiales de otros espacios. El recurso no es novedoso para un género literario que evoca memorias de infancia. ${ }^{x x}$ El texto de Norah Lange

\footnotetext{
xx Estaba presente ya en la novela de Jorge Andrade Proyección en $8 \mathrm{~mm}$ y blanco y negro, durante una reunión de familia, un sábado a la tarde (Barcelona, Muchnik, 1986), que narraba la vida de una
}

Revista Zona Franca- Centro de estudios interdisciplinario sobre las mujeres (CEIM)- Maestría poder y sociedad desde la problemática de género (MG), Rosario, Argentina. ISSN, 2545-6504 http://zonafranca.unr.edu.ar/index.php/ZonaFranca| Número 28 (2020). 
recurría a lo visual y al juego de mirar o ser mirado, a través de su incorporación tanto de la fotografía como del cine. Lograba dar a la narración la tesitura del cinematógrafo del período al que se está haciendo referencia a comienzos del siglo XX, con lo que se reforzaba el efecto de una pátina buscada, es decir, de un artificio. Algo de eso hay en el texto de Szperling en su intención de transportarnos a fines de los años sesenta y a los setenta. ${ }^{\mathrm{XX}}$

Al igual que en el texto de Lange, algo que ya había observado Sylvia Molloy, no se dan marcas temporales precisas que nos ubiquen dentro del acontecer histórico o político (2005: 17). Hay, eso sí, una diferencia en la mención insistente de los años que tiene la narradora, que va puntuando el relato con sus avances o retrocesos: "Tengo siete años. Todavía conservo los miedos, las fantasías y las pesadillas de una niña de cuatro o cinco" (11), "Tengo cuatro años. Hermana Mayor tiene siete." (21), "Tengo nueve años. Victoria, así se llama mi hermana mayor, doce." (42), "Tengo diez años. ¿A dónde ir?" (67), "Tengo trece años. Volvemos de las vacaciones" (109), "Tengo catorce años. A terminó la secundaria, yo empiezo tercero" (142). Este recurso sugiere la construcción de esta narradora en tanto que espectadora -en este caso- de películas de formato casero (sea en Súper ocho o en video).

El escenario de las proyecciones es noctámbulo, como nos alerta ese primer capítulo enteramente dedicado a "Las noches". Allí se suceden varias noches numeradas que producen una especie de rulo temporal, porque el capítulo abre y cierra con anécdotas sucedidas cuando la protagonista tiene siete años. Ese momento, los siete años de la niña, parece anclarla en un presente desde el que la narradora transita por algunos momentos previos: hay escenas de cuando tenía tres años, cuando nace su hermana menor, o de cuando tiene cuatro años. Dicha

familia durante los años del surgimiento del Peronismo, entre 1943 y 1945, mediante la rememoración del hijo, Zeleste.

${ }^{X X I}$ Estas viñetas de infancia se diferencian de otros textos que reconstruyen la niñez y vuelven hacia el pasado, pero sin recurrir a los dispositivos audiovisuales, como es el caso de los textos de Laura Palacios Provincia de Buenos Aires (Rosario, Beatriz Viterbo, 2005) o de Graciela Schvartz, Alma inquieta (Buenos Aires, Edhasa, 2011).

Revista Zona Franca- Centro de estudios interdisciplinario sobre las mujeres (CEIM)- Maestría poder y sociedad desde la problemática de género (MG), Rosario, Argentina. ISSN, 2545-6504 http://zonafranca.unr.edu.ar/index.php/ZonaFrancal Número 28 (2020). 
presentificación imposible revela la situación de espectadora de una película familiar que dispara recuerdos tanto como ensoñaciones. La narradora se pregunta "¿Qué pasa?", y agrega de inmediato: "Estoy atrapada en una pantalla contra la pared del pasillo" (23). El capítulo, además, abre y cierra con ciertos episodios vinculados con el Padre que preanuncian el desenlace con su muerte temprana. Se inicia con Padre rescatándola de su fallido experimento químico que termina con una leve explosión; concluye el capítulo con la internación del Padre a causa de una operación y la visita al hospital. XXII

El carácter espectral de la memoria parece reforzado por ese ámbito nocturno: la noche es el momento ideal para la fantasmagoría. Por eso es que queda flotando en la bruma de la ensoñación la imagen de esta niña que se levanta por las noches y deambula por la casa mientras el resto de sus habitantes duerme. Los sueños se intercalan con los recuerdos y los tiñen de irrealidad. Se mezcla allí una dosis de miedos de infancia contaminando la memoria. Las caras de sus padres y de sus hermanas, "pálidas, de color lunar" (19), reaparecen y actúan al igual que ese haz brillante que la narradora sigue como guía para llegar al foco desde donde proviene la luz, lo que ella misma denomina la "máquina de proyectar sueños". En su sistema de fantasías infantes, esa máquina es manipulada por los padres para distribuir los sueños entre ellas. Y se pregunta: “¿Por qué mis padres me envían pesadillas, sueños oscuros, densos, sueños que no son para una niña de mi edad y dejan los plácidos, alegres y livianos para mis hermanas?" (20).

XXII Al pensar la relación entre infancia y cine Vicky Lebeau nos recuerda que la posibilidad de filmar la vida, particularmente en ese deseo de mostrar la vitalidad de la infancia que lo convierte en un espectáculo privilegiado para la mirada, se convierte en uno de los incentivos principales para el desarrollo del cinematógrafo. El paso de la fotografía a la imagen en movimiento es reivindicado por Méliès como una animación a la vida (2008: pos. 296). La reproducción de la vida se anuda a la idea de su preservación. Permite a las subjetividades del siglo XX poder convertirse en espectadores de sí mismos como niños (pos. 313), lo que contiene en sí cierta nota espectral. Esto genera una nueva forma de temporalidad: la de un desdoblamiento, tanto como la de una comprensión inédita de los momentos en el tiempo. El cine, al permitir acceder a la doble dimensión del niño como espectáculo y como tema, ofrece la posibilidad sin precedentes de combinar para la audiencia adulta la impresión de realidad con el retorno a un punto de vista situado en la infancia (pos. 394).

Revista Zona Franca- Centro de estudios interdisciplinario sobre las mujeres (CEIM)- Maestría poder y sociedad desde la problemática de género (MG), Rosario, Argentina. ISSN, 2545-6504 http://zonafranca.unr.edu.ar/index.php/ZonaFranca| Número 28 (2020). 
Sueños y máquinas parecen enlazarse no solo en el proyector que metaforiza la actividad que tiene lugar cuando se duerme, y que permite imaginar la articulación entre el ámbito de la conciencia y el inconsciente. Se establece un lazo con los sueños en la incubadora que cobija por unos días a la hermana menor cuando nace. La narradora fantasea con esta máquina en términos que aluden a la situación intrauterina, cruzada con un imaginario cibernético: "La imagino encerrada en una especie de licuadora gigante, embadurnada con una grasa mantecosa, maniatada con cablecitos transparentes que transportan alimentos líquidos y sangre fresca" (25). El discurso médico se cuela más adelante, en la NOCHE 12, cuando la niña se refiera a las justificaciones por las que los padres no la llevan al hospital a visitar a la hermana recién nacida. Hay demasiados "aparatos eléctricos, botones, interruptores, enchufes" (27). Para suerte suya, el no poder acceder al lugar le permite imaginarlo como un acuario, una gran pecera de vidrio en donde flotan los bebés junto con los peces, "descansando en el fondo de piedritas, entre las algas y otras plantas acuáticas" (27).

Una cierta tonalidad tiñe los recuerdos y los cubre de una especie de película. Se trata del amarillo que colorea algunos rostros y situaciones como para acentuar su carácter de recuerdos, de momentos pasados, ya algo lejanos. Es el color que proyecta la "máquina", vale decir, la memoria. Traduce una sensación que no es agradable, aunque tiene algo de amniótico, de "sustancia viscosa, pegajosa, amarillenta y calentita" (23). La narradora dice sentirse atrapada por él o, mejor dicho, por la pantalla. Sueño y proyección vuelven a ser equiparados en este fragmento de la NOCHE 8 en el que de manera más explícita la chica reflexiona sobre lo que significa dormir y soñar, porque es capaz de captar narrativamente ese momento de duermevela en el que la conciencia va retornando a la vigilia. En contraste con esa luminosidad difusa y pigmentada, la narradora recupera una noche que ella desearía dejar detenida en el tiempo y en la que el foco de luz proviene de una luna llena "tan grande y luminosa que nuestros cuerpos proyectan

Revista Zona Franca- Centro de estudios interdisciplinario sobre las mujeres (CEIM)- Maestría poder y sociedad desde la problemática de género (MG), Rosario, Argentina. ISSN, 2545-6504 http://zonafranca.unr.edu.ar/index.php/ZonaFranca| Número 28 (2020). 
sombras como si fuese mediodía" (32). Esa otra luz, leída desde un recuerdo feliz no sólo no se le hace espectral, sino que le provoca alivio.

Las menciones al cine o a lo cinematográfico, por otro lado, no abundan. ${ }^{X X I I I}$ Está la anécdota en la que se cae andando en su bicicleta nueva y debe ser llevada al Hospital de Niños. La descripción de la vida en movimiento elige ser narrada mediante el recurso de lo fílmico: "Al pedalear, la imagen empieza a correr. Uno se desliza sobre la superficie y todo a nuestro alrededor se lanza hacia atrás. Todo parece tan quieto y de repente el movimiento lo es todo" (60). Ella se ve como en el interior de una película. Y la voz que comenta sobre este episodio refuerza la idea de sobreimpresión al aclarar que "El cine es siempre un recuerdo de infancia, con el sopor y los sobresaltos y las sorpresas de esas temporadas de niños" (60). Algunos años más tarde, opinará que el departamento en donde vive Félix le hace pensar en un escenario de cine. El edificio es antiguo, pero este departamento de soltero se encuentra decorado con un gusto moderno y artístico, con cierta psicodelia. La protagonista se siente cómoda allí, muy a diferencia de la sensación que le produce su casa con el ambiente enrarecido por la agonía de Padre.

Por último, la muerte del Padre es leída en clave fílmica: la protagonista se percibe como si fuera un personaje de una película de zombis. Ella piensa que de alguna manera también se muere, pero que retorna a la vida bajo la forma de un cuerpo que ya no tiene el control de sus actos. Se pregunta si no estará banalizando la muerte, "eso tan oscuro" (154), mediante un repertorio vinculado con lo que llama "decorados baratos" (154), de películas trash. Luego de este primer impulso autoirónico, opta por definir su estado con mayor precisión como si hubiera perdido la vida que ella quería, una "vida real", para quedar metida en una vida de ficción. Esta

XXIII Con la excepción de la única película mencionada de modo explícito y al que se le dedica un capítulo entero: Belle de Jour. Se ubica en una anécdota de los once años, en la que su amiga Karina le narra en la escuela el argumento de esta película, lo que le valdrá la denuncia de otra compañera y la expulsión. La posibilidad de Karina de ver una película de adultos ya la coloca en un plano diferente, más progresista aun y politizado. Introduce una de las pocas menciones al ambiente político de los años setenta con la radicalización de las clases medias, pero que preanuncia el clima de censura y persecución que arreciarán un par de años más tarde.

Revista Zona Franca- Centro de estudios interdisciplinario sobre las mujeres (CEIM)- Maestría poder y sociedad desde la problemática de género (MG), Rosario, Argentina. ISSN, 2545-6504 http://zonafranca.unr.edu.ar/index.php/ZonaFrancal Número 28 (2020). 
preocupación por los vínculos entre lo falso y lo verdadero, entre lo escenográfico y lo concreto, venía atravesando el relato como uno de los hilos que la narradora vinculaba con la figura de Padre. A diferencia de lo performativo o declamativo ligado a Madre, en esta otra manera de posicionarse frente al mundo circundante el sentido principal es la vista: observar y registrar, todos actos necesarios para definir los modos de ligarse a lo referencial y de estar en el mundo.

David Oubiña nos recuerda los estrechos vínculos entre espectáculo y espectralidad a partir de los prolegómenos del cine y de los "juguetes filosóficos" (la fantasmagoría, el fantascopio, kinesiógrafo, zoopraxistropo, y varios etcéteras) que fueron cimentando el camino del dispositivo audiovisual hasta llegar al siglo XX y a su forma actual. De este derrotero, Oubiña destila la idea de que "toda imagen del movimiento registra no solo la fluidez, la armonía y la continuidad sino también ese otro mundo subterráneo y perturbador que sostiene a lo visible" (2009: 15). No solo porque el cine, al igual que la fotografía, ${ }^{X X I V}$ permite la gran novedad de percibir $y$ de fijar tanto lo involuntario como lo contingente o inesperado. Oubiña agrega que el cine lo que vuelve a representar es, no tanto la escena, como la duración. Hace visible la idea de que el movimiento no consta de una serie de estados acumulativos, sino que supone una transición, un cambio que es cualitativo (22). Esto es lo que le concede al cine su carácter perturbador, porque hace emerger lo que Godard define como la "materia fantasma". La novela de Szperling parece confirmar estas concepciones de la imagen que se ahíncan en imaginarios de larga data y las

XXIV El cine comparte con la fotografía cierto carácter espectral. Roland Barthes lo había planteado desde diversos escorzos en su ensayo Cámara Lúcida (1980). Para empezar, porque en una fotografía se recupera una huella de un referente que existió en el pasado (lo que llama noema), pero que no está más. $Y$, en ese sentido, muestra la catástrofe en la medida en que constituye una actualización permanente de un final que sabemos que va a tener lugar porque lo vemos desde el futuro. Hay una puesta en escena, lo que para Barthes emparenta a la foto más con el teatro que con el cine. Posar para la foto supone una micro-versión de la muerte: se pasa de ser sujeto a ser objeto. De ahí que denomine Spectrum a lo fotografiado, sea una persona o una cosa. Implica una forma de simulacro, a la vez que de espectáculo que hace retornar a los muertos: una fantasmagoría. Por último, Barthes concluye que el espectador busca en la fotografía una forma de reconocimiento, sobre todo de la persona amada. Esa reconstrucción solo puede darse de manera fragmentada desde el momento en que esa persona no está más. La foto permite el avenir de un algo que logra amalgamar esos elementos dispersos, el detalle (a veces caprichoso) que interpela al espectador porque lo afecta, lo que el llamará Punctum.

Revista Zona Franca- Centro de estudios interdisciplinario sobre las mujeres (CEIM)- Maestría poder y sociedad desde la problemática de género (MG), Rosario, Argentina. ISSN, 2545-6504 http://zonafranca.unr.edu.ar/index.php/ZonaFranca| Número 28 (2020). Página 407 
reutiliza para la configuración de un relato que oscila entre lo memorialístico y lo privado, siempre moviéndose en los hiatos que abre el acto de narrar.

\section{La astucia de la narración}

El texto funciona como pantalla en varios sentidos. La palabra emula un sistema de proyecciones que involucra dispositivos ópticos que hoy ya forman parte de la cotidianeidad y de los espacios domésticos; por el otro, la referencia apunta a funciones psíquicas como la imaginación, las fantasías y los sueños. Estamos ante una subjetividad que reflexiona sobre los modos en que se construye la memoria individual y familiar, de un yo cinemático que se va armando a partir del montaje y que nunca termina de concluirse. La puesta en escena de esto se ve al final, con el testimonio de la amiga que le permite no solo revivir sino re-armar un momento revulsivo de la propia biografía, lo que lleva a re-acomodar todo lo que la protagonista sabía de sí misma. ${ }^{\mathrm{x} v}$

A ese plano se suma otro que es colectivo. Leonor Arfuch lo piensa cuando busca definir los alcances de todas aquellas narraciones que ella agrupa bajo la noción de "espacio biográfico" y que forman parte de un repertorio variopinto y en expansión. Arfuch concluye que se trata de un lugar singular pero habitado por la pluralidad, que nos sitúa en un "umbral de visibilidad indecidible entre público y privado" (2010: 248). Los comienzos de la modernidad ya habían puesto en evidencia su carácter paradójico y difícil de resolver mediante un sistema antinómico. Es decir, el de ser un espacio entre, que revela la imbricación profunda entre individuo y sociedad. Al pensar a ciertas narrativas del pasado que suponen lo común pero que colocan en el centro de la trama lo autorreferencial, Arfuch añadirá que la expresión subjetiva adquiere otras connotaciones cuando se articula

\footnotetext{
$x x v$ En esta escena está funcionando a pleno la idea de trauma y de huella. Arfuch se refiere a esa huella afectiva como una "impronta imaginaria" (2013: 64) y que responde a una imagen que viene de otro lado, no del "asedio visual cotidiano". El olvido de la escena traumática queda en tanto que huella inconsciente que funciona como mecanismo de supervivencia. En la imagen subyace ese fondo que se escapa porque está refiriéndose a una ausencia.
}

Revista Zona Franca- Centro de estudios interdisciplinario sobre las mujeres (CEIM)- Maestría poder y sociedad desde la problemática de género (MG), Rosario, Argentina. ISSN, 2545-6504 http://zonafranca.unr.edu.ar/index.php/ZonaFranca| Número 28 (2020). Página 408 
con el "horizonte problemático de lo colectivo" (2013: 13). Lo comunitario implica tanto la memoria como el imaginario, las representaciones como las identidades. Las zonas en las que lo biográfico se enlaza con lo memorial son fronterizas, y por eso le interesan. Porque allí es que puede rastrear las "tramas (sociales) del afecto" (14).

El recorrido textual al que nos conduce la "fábula autobiográfica" de Szperling se encuentra situada en una escenografía urbana y en un tiempo de cambios sustanciales para hombres y mujeres, que será movilizada sobre todo por ellas. Es un momento en el que se ponen en entredicho mandatos familiares y se tuercen los modos de vincularse entre los géneros. Por lo tanto, no resulta ocioso volver la mirada hacia ese período desde una narración que se interna en los tejidos más íntimos y menos visibles; no en los grandes hechos estentóreos, sino en algo mucho más capilar. La mirada se empequeñece porque se vuelve microscópica. La máquina de proyectar sueños emite ráfagas de sensaciones olvidadas, que no están en los archivos historiográficos, sino que quedaron en los pliegues de las experiencias personales de una generación situada. Al hablar de su novela, Szperling repite que ella la concibió como una serie de piezas musicales, de canciones o textos para recitar. De ahí la fragmentación sumada a lo performático, pero también el trabajo colectivo que incluye la imagen de tapa de Flavia Da Rin. Es una novela para tararear; una que, de alguna manera, sabemos todas y todos.

Lo visual, en tanto que inseparable de la construcción de una memoria social, aparece aquí como expresión de la puesta en acto de una performance. AnneEmmanuelle Berger nos recuerda que la mascarada viene con una historia para nada novedosa, sino vinculada con nuestro destino de animales sociales. El género, por su parte, está desde siempre como un señuelo (2016: 40). Por lo que Berger prefiere hablar de escena de género o de "teatro de la identidad sexual" (43, cursivas en el original), en la que rol de género y seducción, puesta en escena, son todos elementos que van de la mano. Ahí no hay solo seductor y seducido: el rol seduce tanto al que interpreta como al que observa. La novela de Cecilia Szperling, su

Revista Zona Franca- Centro de estudios interdisciplinario sobre las mujeres (CEIM)- Maestría poder y sociedad desde la problemática de género (MG), Rosario, Argentina. ISSN, 2545-6504 http://zonafranca.unr.edu.ar/index.php/ZonaFranca| Número 28 (2020). 
"fábula autobiográfica", demuestra tener una clara noción del funcionamiento de lo performativo, fruto de la combinación entre las diversas posibilidades que brinda el arte y que la teatralidad logra amalgamar. La literatura, por su parte, como metonimia de una biblioteca, permite dar cuerpo al archivo que fija mediante la letra y guarda, como en una cajita, esta sucesión de recuerdos.

\section{Bibliografía}

AMíCOLA, José (2007) Autobiografía como autofiguración. Estrategias discursivas del yo y cuestiones de género. Rosario: Beatriz Viterbo/CINIG.

ARFUCH, Leonor (2010 [2002]) El espacio biográfico. Buenos Aires: FCE.

ARFUCH, Leonor (2013). Memoria y Autobiografía. Exploraciones en los límites. Buenos Aires: FCE.

BARTHES, Roland (1989 [1980]) La cámara Lúcida. Nota sobre la fotografía. Barcelona, Paidós.

BERGER, Anne-Emmanuelle (2016) El gran teatro del género. Identidades, sexualidades y feminismos. Buenos Aires: Mardulce.

BUTLER, Judith (2009 [2006]). Vida precaria. El poder del duelo y la violencia. Trad. Fermín Rodríguez. Buenos Aires, Paidós.

CARLI, Sandra (2011) "Los escritos autobiográficos de Norah Lange y Arturo Jauretche", en La memoria de la infancia. Estudios sobre historia, cultura y sociedad. Buenos Aires: Paidós, 21-51.

DIDI-HUBERMAN, Georges (2011) Atlas ou le gai savoir inquiet. L'oeil de I'histoire, 3. Paris: Les Éditions de Minuit.

FRIERA, Silvina (2016) "La autobiografía para mí fue como un antídoto", Página/12, Cultura y espectáculos, 19 de diciembre de 2016, (Acceso: 15/06/2020), https://www.pagina12.com.ar/9564-la-autobiografia-para-mi-fue-como-un-antidoto.

LANGE, Norah (2005) Obras completas. Tomo I. Edición al cuidado de Adriana Astutti. Rosario: Beatriz Viterbo.

LEBEAU, Vicky (2008) Childhood and cinema. London: Reaktion Books. Kindle Edition.

Revista Zona Franca- Centro de estudios interdisciplinario sobre las mujeres (CEIM)- Maestría poder y sociedad desde la problemática de género (MG), Rosario, Argentina. ISSN, 2545-6504 http://zonafranca.unr.edu.ar/index.php/ZonaFrancal Número 28 (2020). 
LEGAZ, María Elena (2010) "Las metáforas de la muerte", en Adriana Astutti y Nora Domínguez (comps.) Promesas de tinta. Diez ensayos sobre Norah Lange. Rosario: Beatriz Viterbo, 79-91.

LERER, Seth (2008) Children's Literature. A reader's History, from Aesop to Harry Potter. Chicago and London: Chicago University Press. Kindle Edition.

MÉNDEZ, Matías (2016) "Escribí un libro para las pesadillas de la noche, Infobae, Cultura, 26 de junio de 2016. (Acceso: 15/06/2020) https://www.infobae.com/cultura/2016/06/26/cecilia-szperling-escribi-un-libro-paralas-pesadillas-de-la-noche/.

MOLLOY, Sylvia (1996 [1991]) Acto de presencia. La escritura autobiográfica en Hispanoamérica. México: FCE.

MOLLOY, Sylvia (2005) "Una tal Norah Lange”, en Obras completas. Tomo I. Edición al cuidado de Adriana Astutti. Rosario, Beatriz Viterbo, 9-28.

OUBIÑA, David (2009) Una juguetería filosófica: Cine, cronofotografía y arte digital. Buenos Aires: Manantial.

PEKER, Luciana (2019). La revolución de las hijas. Buenos Aires, Paidós.

PUNTE, María José (2016) "La estrategia de una Mirada infanceada en Cuadernos de infancia de Norah Lange", en Germán Prósperi (coord.) Debates actuales del hispanismo: balances y desafíos críticos. Actas del X Congreso Argentino de Hispanistas. Santa Fe: UNL, 2016.

PUNTE, María José (2018) Topografías del estallido. Figuras de infancia en la literatura argentina. Buenos Aires: Corregidor.

SIERRA, Marta J. (2005) "Oblique Views: Artistic Doubling, Ironic Mirroring and Photomontage in the Works of Norah Lange and Norah Borges", Revista Canadiense de Estudios Hispánicos, Vol. 29, Nro. 3 (primavera 2005), 563-584.

SZPERLING, Cecilia (2016) La máquina de proyectar sueños. Fábula autobiográfica. Buenos Aires: Interzona.

Revista Zona Franca- Centro de estudios interdisciplinario sobre las mujeres (CEIM)- Maestría poder y sociedad desde la problemática de género (MG), Rosario, Argentina. ISSN, 2545-6504 http://zonafranca.unr.edu.ar/index.php/ZonaFrancal Número 28 (2020). 